\title{
Testicular and Spermatic Cord Metastases from Gastric Adenocarcinoma: An Unusual Case
}

This article was published in the following Dove Press journal:

Cancer Management and Research

Jing $\mathrm{Fu}^{1,2}$

Jindan Luo'

Huajian $\mathrm{Ye}^{2}$

Yaokang Chen ${ }^{2}$

Liping Xie'

'Department of Urology, The First Affiliated Hospital, College of Medicine, Zhejiang University, Hangzhou, Zhejiang, 3I0003, People's Republic of China; ${ }^{2}$ Department of Urology, Shaoxing Second Hospital, Shaoxing, Zhejiang, 3/2000, People's Republic of China

\begin{abstract}
The metastasis of gastric cancer to the testis or spermatic cord is very rare; however, simultaneous testicular and spermatic cord metastases are even rarer. Here, we report an unusual case of a 54-year-old male patient who had undergone radical gastrectomy for gastric adenocarcinoma more than two years before. He complained of palpable painful masses in the right scrotum and inguinal area occurring for more than half a year. Enhanced computed tomography (CT) separately showed an enhanced soft tissue mass in the right testicular and spermatic cord areas. Therefore, a right radical orchiectomy was conducted. The pathology was consistent with the metastases of gastric adenocarcinoma.
\end{abstract}

Keywords: gastric adenocarcinoma, testis, spermatic cord, metastasis

\section{Introduction}

Gastric cancer has a high incidence and mortality worldwide, which significantly threatens public health. The incidence of gastric cancer ranks fifth among various malignant tumours worldwide. ${ }^{1}$ Gastric cancer is the 2 nd leading cause of death from malignant tumours globally and the 3rd leading cause in China. ${ }^{2,3}$ The metastasis of gastric cancer is a fatal step that indicates a poor prognosis. Male reproductive system metastasis from gastric cancer is extremely rare. Here, we report an unusual case of a 54-year-old male patient with right testicular and spermatic cord metastases of gastric adenocarcinoma more than two years after radical gastrectomy.

\section{Case Report}

A 54-year-old man complained of palpable painful masses in the right scrotum and inguinal area that had been observed for more than half a year. The patient had undergone radical gastrectomy (Billroth II) for gastric adenocarcinoma more than two years before. The histologic evaluation of the surgical specimens revealed poorly differentiated adenocarcinoma (T3N2M0, stage IIIA). He had received tegafur and oxaliplatin chemotherapy for 8 cycles. There was no sign of tumour recurrence during the two-year follow-up.

His physical examination showed that there was a $3 \mathrm{~cm} \times 2 \mathrm{~cm}$ mass above the right testis and a $2 \mathrm{~cm} \times 1 \mathrm{~cm}$ mass in the right inguinal area. The masses were hard, lumpy and tender. The right spermatic cord became thicker. Carbohydrate antigen 242 (CA242) was $62.73 \mathrm{IU} / \mathrm{mL}$, and the levels of other tumour markers, including carcinoembryonic antigen (CEA), carbohydrate antigen 19-9 (CA19-9), carbohydrate antigen 125 (CA125), prostate-specific antigen (PSA), alpha-fetoprotein
Correspondence: Liping Xie

Department of Urology, The First

Zhejiang University, No. 79 Qingchun

Road, Hangzhou, Zhejiang, 310003,

People's Republic of China

$\mathrm{Tel} / \mathrm{Fax}+86$ 57/ 87072577

Email xielp@zju.edu.cn

Yaokang Chen

Department of Urology, Shaoxing Second

Hospital, No. 123 Yanan Road, Shaoxing,

Zhejiang, 3 2000, People's Republic of

China

Tel +8657588053825

Email768035669@qq.com
Cancer Management and Research 2021:13 1897-1900

1897

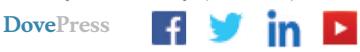

(c) (1) (5) 202I Fu et al. This work is published and licensed by Dove Medical Press Limited. The full terms of this license are available at https://www.dovepress.com/terms.php you hereby accept the Terms. Non-commercial uses of the work are permitted without any further permission from Dove Medical Press Limited, provided the work is properly attributed. For permission for commercial use of this work, please see paragraphs 4.2 and 5 of our Terms (https://www.dovepress.com/terms.php). 


\section{A}

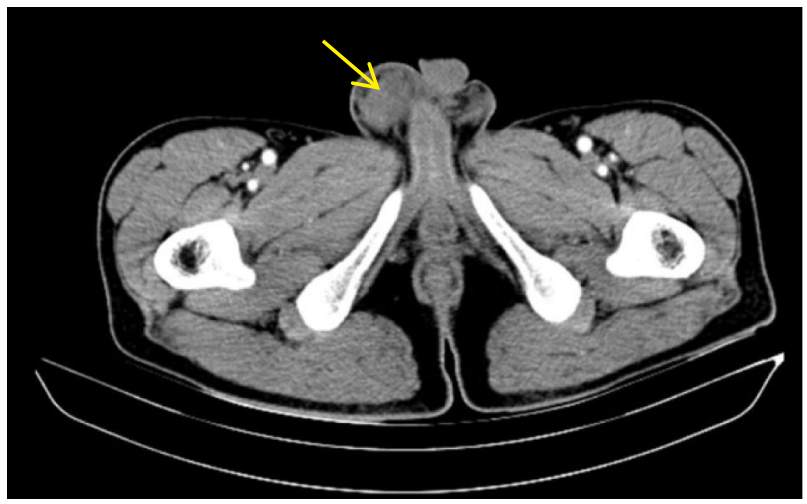

B

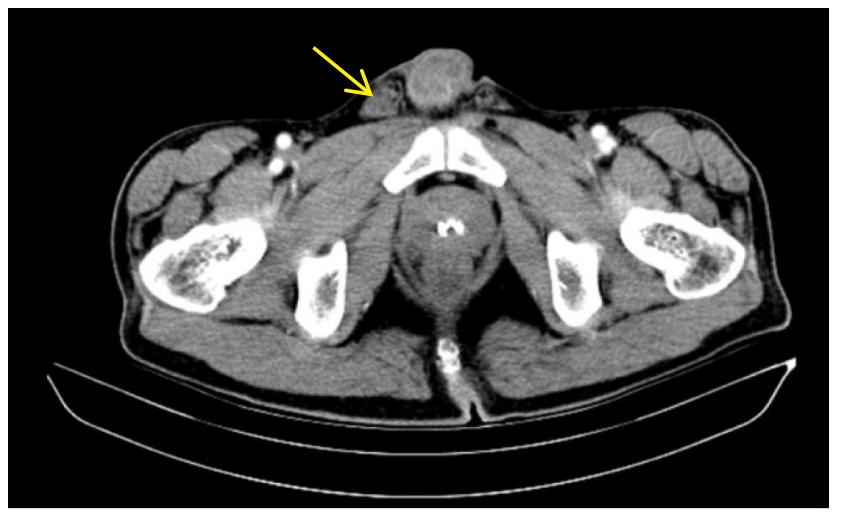

Figure I Enhanced computed tomography images. (A) Metastatic tumour of the right testis (arrow); (B) Metastatic tumour of the right spermatic cord (arrow).

(AFP), and $\beta$-human chorionic gonadotropin ( $\beta$-HCG), were all in the normal reference ranges. Scrotal B-ultrasound revealed the right hydrocele of the testis, the right thick spermatic cord and uneven local echo. Then, enhanced computed tomography (CT) separately showed an enhanced soft tissue mass in the right testicular and spermatic cord areas (Figure 1). A biopsy of spermatic cord mass suggested adenocarcinoma invasion. As a result, the patient was treated by right radical orchiectomy through the inguinal approach under general anaesthesia. The pathology was consistent with the metastases of gastric adenocarcinoma (Figure 2). Although the spermatic cord tissue was removed as much as possible, the infiltration of cancer cells was still seen in the surgical margin of the spermatic cord. Thus, the patient received tegafur and oxaliplatin chemotherapy again, there was no evidence of recurrence at the half-year follow-up, and CA242 levels returned to the normal value.

\section{Discussion}

Gastric cancer metastasis gives rise to an important reason for treatment failure and causes death in gastric cancer patients. Because of the deficiency of appropriate early diagnostic approaches, many patients diagnosed with gastric cancer are at an advanced stage. Liver metastasis is most frequent, and abdominal implantation metastasis can also occur. However, testicular and spermatic cord metastases from gastric cancer are extremely unusual.

Metastases of malignant tumours to the testis or spermatic cord are very rare. The testes are wrapped by tunica albuginea, have a relatively low temperature, and are suspended in the scrotum. Therefore, testicular metastasis is rare. Less than $2.5 \%$ of testicular malignant tumours come from metastases, and the most common primary sites are the prostate and lung. ${ }^{4,5} \mathrm{~A}$ total of $8.1 \%$ of spermatic cord malignancies are metastatic tumours, ${ }^{6}$ and the gastrointestinal tract is the most common source, followed by the
A

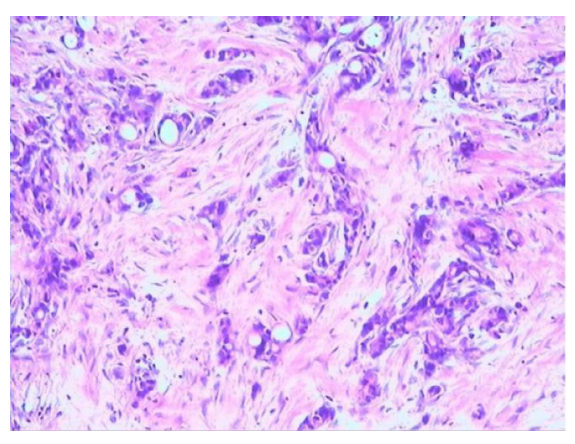

B

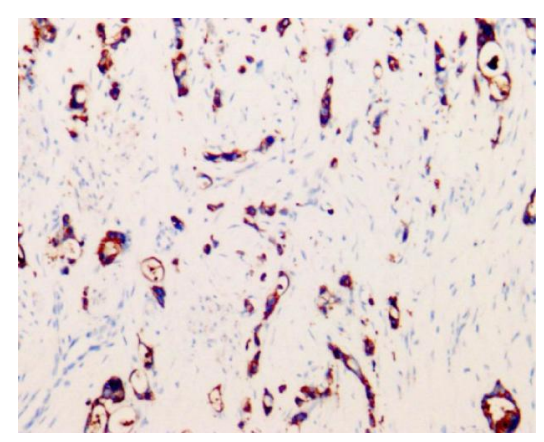

C

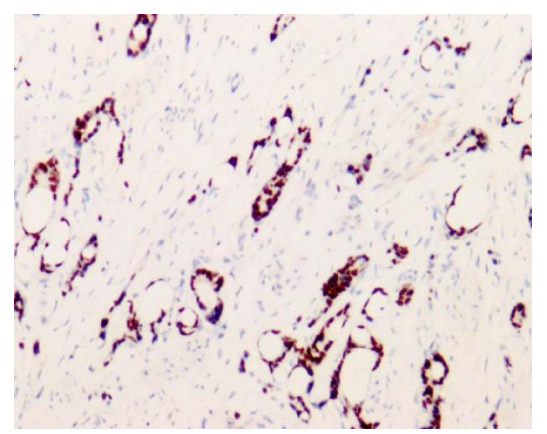

Figure 2 Pathological results of testicular and spermatic cord metastases from gastric adenocarcinoma. (A) Infiltration of adenocarcinoma cells (haematoxylin-eosin staining, original magnification: $\times 100)$. (B-C) Immunohistochemistry showed that the tumour cells were positive for pancytokeratin (CK) 8-Auto and CK (L)-Auto. 
pancreas, prostate, and kidney. ${ }^{7}$ Thus, it is even rarer that malignant tumour can metastasize to the testis and spermatic cord simultaneously. Velaga et $\mathrm{al}^{8}$ reported only one case of extramedullary multiple myeloma of the testes and left spermatic cord. Dai et $\mathrm{al}^{9}$ reported that gastric cancer metastasized to the male genital system. A total of 27 cases of male genital metastasis from gastric cancer were reviewed from 1955 to 2016 . Only six patients had both testicular and spermatic cord metastases. Herein, a patient with gastric adenocarcinoma who developed metastasis to the testis and spermatic cord is presented.

In the case presented, the initial symptoms of the patient were scrotal and inguinal painful masses. Scrotal or inguinal masses are the most common symptom of male genital metastasis. Furthermore, some patients may manifest hydrocele and scrotal swelling. ${ }^{9}$ Because of the atypical symptoms, it is easily misdiagnosed as a primary tumour of the male genital system, hernia, epididymitis and spermatitis. Therefore, a medical history inquiry must be considered. If there is a history of nonreproductive system tumours, then metastatic tumours of the reproductive system should not be ignored. Although tumour markers such as CA19-9, CA242 and CEA and imaging examinations such as B-ultrasound, CT, magnetic resonance imaging (MRI) and positron emission tomography CT (PET-CT) can help to make a definitive diagnosis, the final diagnosis still depends on biopsy and histopathological examination. For patients with reproductive system metastasis only, if the metastasis can be evaluated as a resectable tumour, radical resection and adjuvant radiochemotherapy can obtain significantly longer survival. ${ }^{4,10}$

The specific mechanism of gastric cancer metastasis to the testis or spermatic cord is still obscure. A series of biological changes are involved in the metastasis of gastric cancer cells. They include (1) the invasion of gastric cancer cells into protective barriers and migration to adjacent tissues; (2) the invasion of gastric cancer cells into blood vessels and haematogenous metastasis; (3) the invasion of gastric cancer cells into the lymphatic system and dissemination; and (4) the detachment of gastric cancer cells from the primary tumour and adhesion to sensitive sites. Park et al ${ }^{11}$ proposed the overlap of metastasis pathways between gastric cancer and testicular cancer, and retrograde metastatic spread led to testicular and spermatic cord metastasis. Li et $\mathrm{al}^{12}$ suggested that because the function of the processus vaginalis was incomplete, gastric cancer cells spread to the testis through the patent processus vaginalis. It was considered that gastric cancer could metastasize to male genital organs due to haematogenous spread, especially in cases with paraneoplastic leukaemoid reactions. ${ }^{13}$ At present, it is believed that gastric cancer cells are most likely to metastasize to the spermatic cord through the blood or lymphatic pathways.

Generally, the metastasis of gastric cancer to the testis or spermatic cord is very rare. However, simultaneous testicular and spermatic cord metastases are even rarer. The report of this rare case will help us to heighten our vigilance in clinical practice. For patients with scrotal or inguinal masses, aetiology outside the scrotum should not be ignored in diagnosis.

\section{Ethics Statement}

Written informed consent was been obtained from the patient to obtain the case details and any accompanying images published. Institutional approval was required to publish the case details. The study was approved by the Ethics Committee of Shaoxing Second Hospital. This study was performed in accordance with the declaration of Helsinki.

\section{Disclosure}

The authors declare no conflicts of interest in this work.

\section{References}

1. Allemani C, Weir HK, Carreira H, et al. Global surveillance of cancer survival 1995-2009: analysis of individual data for 25,676,887 patients from 279 population-based registries in 67 countries (CONCORD-2). Lancet. 2015;385(9972):977-1010. doi:10.1016/ S0140-6736(14)62038-9

2. Torre LA, Bray F, Siegel RL, Ferlay J, Lortet-Tieulent J, Jemal A. Global cancer statistics, 2012. CA Cancer J Clin. 2015;65(2):87-108. doi: $10.3322 /$ caac. 21262

3. Chen W, Zheng R, Baade PD, et al. Cancer statistics in China, 2015. CA Cancer J Clin. 2016;66(2):115-132. doi:10.3322/caac.21338

4. Yang KC, Chao Y, Luo JC, et al. The unusual presentation of gastric adenocarcinoma as a testicular mass: a favorable response to docetaxel and cisplatin plus oral tegafur/uracil and leucovorin. J Chin Med Assoc. 2010;73(2):88-92. doi:10.1016/S1726-4901(10)70007-1

5. Sarier M, Tunç M, Özel E, et al. Evaluation of histopathologic results of testicular tumors in Antalya: multi center study. Bull Urooncol. 2020;19:64-67. doi:10.4274/uob.galenos.2019.1412

6. Beccia DJ, Krane RJ, Olsson CA. Clinical management of non-testicular intrascrotal tumors. J Urol. 1976;116(4):476-479. doi:10.1016/s0022-5347(17)58867-9

7. Algaba F, Santaularia JM, Villavicencio H. Metastatic tumor of the epididymis and spermatic cord. Eur Urol. 1983;9(1):56-59. doi:10.1159/000474045

8. Velaga J, Liang HH, Gopalakrishnan SK. Multiple myeloma of testes and spermatic cord on 18F-FDG PET/CT. Clin Nucl Med. 2019;44 (4):297-298. doi:10.1097/RLU.0000000000002462

9. Dai WG, Liu DW, Zuo JD, et al. Metastatic tumor of male genital system from gastric cancer: a case report and review of literature. Int J Clin Exp Pathol. 2017;10(8):8592-8598. 
10. Kim JH, Kim DS, Cho HD, Lee MS. Late-onset metastatic adenocarcinoma of the spermatic cord from primary gastric cancer. World J Surg Oncol. 2014;12(1):128. doi:10.1186/1477-7819-12-128

11. Park S, Moon SK, Lim JW. Mechanism of metastasis to the spermatic cord and testis from advanced gastric cancer: a case report. $B M C$ Gastroenterol. 2020;20(1):119. doi:10.1186/s12876-020-01269-0

12. Li B, Cai H, Kang ZC, Wu H, Hou JG, Ma LY. Testicular metastasis from gastric carcinoma: a case report. World $J$ Gastroenterol. 2015;21(21):6764-6768. doi:10.3748/wjg.v21.i21.6764
13. Guven EO, Selvi I, Kilciler M, Basar H. Malign priapism secondary to renal cell carcinoma provoked paraneoplastic leukemoid reaction: report of the first case. Acta Oncol Tur. 2018;51(2):259-262. doi:10.5505/aot.2018.64426

\section{Publish your work in this journal}

Cancer Management and Research is an international, peer-reviewed open access journal focusing on cancer research and the optimal use of preventative and integrated treatment interventions to achieve improved outcomes, enhanced survival and quality of life for the cancer patient.
The manuscript management system is completely online and includes a very quick and fair peer-review system, which is all easy to use. Visit http://www.dovepress.com/testimonials.php to read real quotes from published authors. 